Ege Tıp Dergisi / Ege Journal of Medicine 2021; 60 (4): 402-406

\title{
Acil serviste tıbbi sosyal hizmet müdahalesi gereksinimi olan hastaların retrospektif değerlendirilmesi
}

\author{
Retrospective evaluation of patients who need social service interview in \\ emergency department
}

\author{
Sercan Yalçınlı (D) Funda Karbek Akarca BDa Yerdelen \\ Ege Üniversitesi Tıp Fakültesi Hastanesi Acil Tıp Anabilim Dalı, İzmir, Türkiye
}

ÖZ

Amaç: Bu çalışmada, bir üçüncü basamak üniversite hastanesi acil servisine başvuran ve sosyal hizmet değerlendirmesi yapılan hastaların özellikleri araştırıldı.

Gereç ve Yöntem: Acil servise 2012-2019 yılları arasında başvuran ve sosyal hizmet değerlendirmesi yapılan hastalar çalışmaya dahil edildi. Hasta dosya kayıtları retrospektif olarak taranarak, hastaların demografik ve klinik özellikleri araştıııldı.

Bulgular: Çalışma popülasyonu 243 hastadan oluştu. Ortalama yaş 55,6 $\pm 20,3$ olarak belirlendi ve hastaların \%65,8'i erkekti (n:160). Sosyal hizmet değerlendirmesinin talep edilmesinin en yaygın nedenleri, hastaların barınma $(\% 36,2)$, ulaşım $(\% 30,0)$ ve rehberlik hizmetleri $(\% 18,9)$ intiyaçlarıydı. Sosyal hizmet birimi tarafından hastalara en sık; danışmanlık $(\% 28,4)$, hasta yakınlarına ulaşma (\%23), Aile, Çalışma ve Sosyal Hizmetler İ Müdürlüğü ile temasa geçilmesi (\%20,6), psiko-sosyal görüşme $(\% 15,2)$ şeklinde hizmet verildiği belirlendi. Hastaların sosyal hizmet birimi değerlendirmesi sonrası \% 35,7'sinin kuruma yönlendirildiği (n:84), \%23,4'ünün yakınlarına teslim edildiği (n:55), $\% 16,6$ 'sının da kuruma yerleştirildiği (n:39) saptandı.

Sonuç: Acil servislerde sosyal hizmet uzmanı değerlendirmesine ihtiyaç duyulur. Barınma ve ulaşım sorunları en sık sosyal hizmet desteği istenme nedenleridir. Acil servis çalışanlarının sosyal hizmet uygulamalarının kapsamı hakkında farkındalıklarının artırıması gerekir. Acil servislerde tam zamanlı sosyal hizmet görevlilerinin daha fazla hastaya temas edebilmek için bulunması gereklidir.

Anahtar Sözcükler: Tıbbi sosyal hizmet, acil servis, sosyal hizmet uzmanı.

\begin{abstract}
Aim: In this study, we wanted to investigate the characteristics of patients who applied to a tertiary university hospital emergency department and underwent social service assessment.

Materials and Methods: We included patients who presented to the emergency department between 2012 and 2019 and underwent social service assessment. We retrospectively searched the demographic and clinical characteristics of the patients by patient file records.

Results: The study population consisted of 243 patients. The mean age was $55.6 \pm 20.3$ years, and $65.8 \%$ ( $n: 160)$ of the patients were male. The most common reasons for requesting social work evaluation are accommodation (36.2\%), transportation (30.0\%), and guidance services (18.9\%) needs of patients. The most common supports of social workers occurred as; counseling (28.4\%), reaching relatives (23\%), contacting the Provincial Directorate of Family, Labor and Social Services (20.6\%), and psycho-social interview (15.2\%). After the evaluation, it was determined that the social workers referred $35.7 \%$ ( $n: 84)$ of the patients to the institution, $23.4 \%$ delivered to their relatives ( $n: 55)$, and $16.6 \%$ ( $n: 39)$ placed in the institution.
\end{abstract}

\footnotetext{
Sorumlu yazar: Sercan Yalçınlı

Ege Üniversitesi Tıp Fakültesi Hastanesi Acil Tıp Anabilim Dalı,

İzmir, Türkiye

E-posta: sercanyalcinli@yahoo.com.tr

Başvuru tarihi: 25.05.2021 Kabul tarihi: 31.07.2021
} 
Conclusion: There is a need for social workers in emergency departments. Accommodation and transfer problems are the most common reasons for seeking social service support. The awareness of emergency medicine professionals about the scope of social work practices should be increased. Fulltime social workers need to be present in emergency departments to be able to contact more patients.

Keywords: Medical social work, emergency medicine, medical social worker.

\section{GíRiş}

Acil servisler başvuranlara sosyo-ekonomik durumlarına bakılmaksızın eşit şekilde sağlık hizmeti verilen hastane birimleridir. Bu hizmetin sunumu sırasında zaman zaman psiko-sosyal veya sosyo-ekonomik açıdan dezavantajlı (kimsesiz, engelli, şiddet mağduru, göçmen vb.) hasta grupları ile karşılaşılmaktadır. Acil servisler dezavantajı grupların sağlık hizmetlerinden faydalanabilmeleri açısından önemli bir erişim noktasıdır (1). Acil servis başvurusuna yol açan tıbbi durum kadar bu hastaların tedavi sırasında ve sonrasında yeterli sosyal desteğe ulaşabilmeleri de önemlidir. Klasik hekim-hasta temelli yaklaşım hastaların sosyal sorunlarını çözmekte yetersiz kalır ve acil servislerde kalış süreleri uzar aynı zamanda gereksiz hastane yatışları yapılabilir (2). Böyle durumlarda disiplinler arası işbirliğinin sağlanabilmesi için sosyal hizmet desteği almak kaçınılmazdır (3). Sosyal hizmet desteğinin sağlanması hastaların acil servislerde geçirdikleri sürelerde kısalmayı, sosyal güvence sisteminden faydalanmalarını ve daha az hastane yatış intiyacını sağlamaktadır $(2,4)$. Bu hizmetin sağlanmasında arzu edilen durum acil servis işleyişine uygun olarak 7/24 sosyal hizmet yetkililerine ulaşmak olsa da bu destek çoğu zaman mesai saatleri içerisinde karşılanır (5).

Literatürde ulusal ölçekte acil servislerde sosyal hizmet gereksinimi olan hastaların değerlendirildiği yeterli çalışma bulunmamaktadır. Özellikle acil serviste hangi hasta profilinin bu desteğe daha çok intiyaç duyduğu, sosyal hizmet desteği alan hastaların sonlanışlarının nasıl olduğu gibi demografik ve tanımlayıcı verilerin sunulduğu kısıtlı çalışma bulunmaktadır. Bu çalışmada acil serviste sosyal hizmet uzmanı desteği alan hastaların tanımlayıcı verileri araştırılarak literatüre katkı sunulması hedeflenmiştir.

\section{GEREÇ ve YÖNTEM}

Retrospektif tanımlayıcı bir araştırma gerçekleştirildi. Araştırma evrenini 2012-2019 yılları arasında bir 3 . basamak üniversite hastanesi acil servisine başvuran ve sosyal hizmet uzmanı değerlendirmesine tabi tutulan hastalar oluşturdu. Araştırmaya başlamadan önce etik kurul onayı alındı (Karar No: 21-
1.1T/54). Hastaların verileri 2017-2019 yılları arasında elektronik hasta dosyaları üzerinden, 2012-2016 yılları arasında ise hasta kartları üzerinden elde edildi. Bu kapsamda hastaların; yaş, cinsiyet, acil servis de kalış süreleri (saat olarak), acil servise başvuru şekilleri (112, ayaktan, diğer), sosyal güvencesi, acil servis başvuru nedeni (medikal, madde alımı, şiddet, psikiyatrik, palyatif), acil servis son tanısı, sosyal hizmet değerlendirme nedeni (madde alımı, rehberlik, barınma talebi, ulaşım talebi, intihar, adli vaka, şiddet, diğer), sosyal hizmet katkısı (psiko-sosyal görüşme, danışmanlık, il müdürlüğü ile görüşme, belediye hizmetleri, yakınlarına ulaşma, güvenli ulaşım), sosyal hizmet değerlendirmelerinin sonlanma şekli (kuruma yerleştirildi, kuruma yönlendirildi, yakınlarına teslim edildi, güvenli ulaşım sağlandı, taburculuğu sağlandı), acil servis sonlanım şekli (taburcu, sevk, yatış, eksitus, izinsiz terk) gibi değişkenler incelendi.

İstatistiksel değerlendirmeler için SPSS 25.0 programı kullanıldı. Değişkenlerin normal dağılıma uygunluğu incelendi. Tanımlayıcı analizler normal dağılan sürekli değişkenler için ortalama ve standart sapmalar kullanılarak verildi. Nominal ve ordinal veriler için tanımlayıcı istatistikler frekanslar ve yüzdeler kullanılarak verildi.

\section{BULGULAR}

Araştırma için toplam 295 hasta dosyası tarandı. Dosya kayıtlarının yetersizliği nedeni ile 52 hasta çalışma dışı bırakıldı. Çalışma verileri toplamda 243 hasta üzerinden değerlendirildi. Hastaların $\% 65,8$ 'ini (n:160) erkek cinsiyet oluşturdu. Yaş ortalaması 55,6 \pm 20,3 (minimum: 13, maksimum: 94) olarak belirlendi. Hastaların acil servise en sık 112 aracılığı ile getirildiği anlaşıldı (n:169, $\% 70,1)$. Barınma durumu açısından hastaların $\% 71,1^{\prime} i$ (n:172) evde ikamet ederken, \%23,1'inin (n:56) evsiz (bimekan) olduğu belirlendi. Hastaların \%88,2'sinin (n:212) bir sosyal güvencesinin olduğu saptandı. Acil servis tanıları \% 55,6 ile medikal sorunlar (n: 135) kaynaklı iken bu durumu \%18,1 ile psikiyatrik nedenlerin (n:44) ve $\% 16,5$ ile palyatif sorunların (n:40) izlediği gözlendi. 
Tablo-1. Hastaların demografik ve klinik özellikleri.

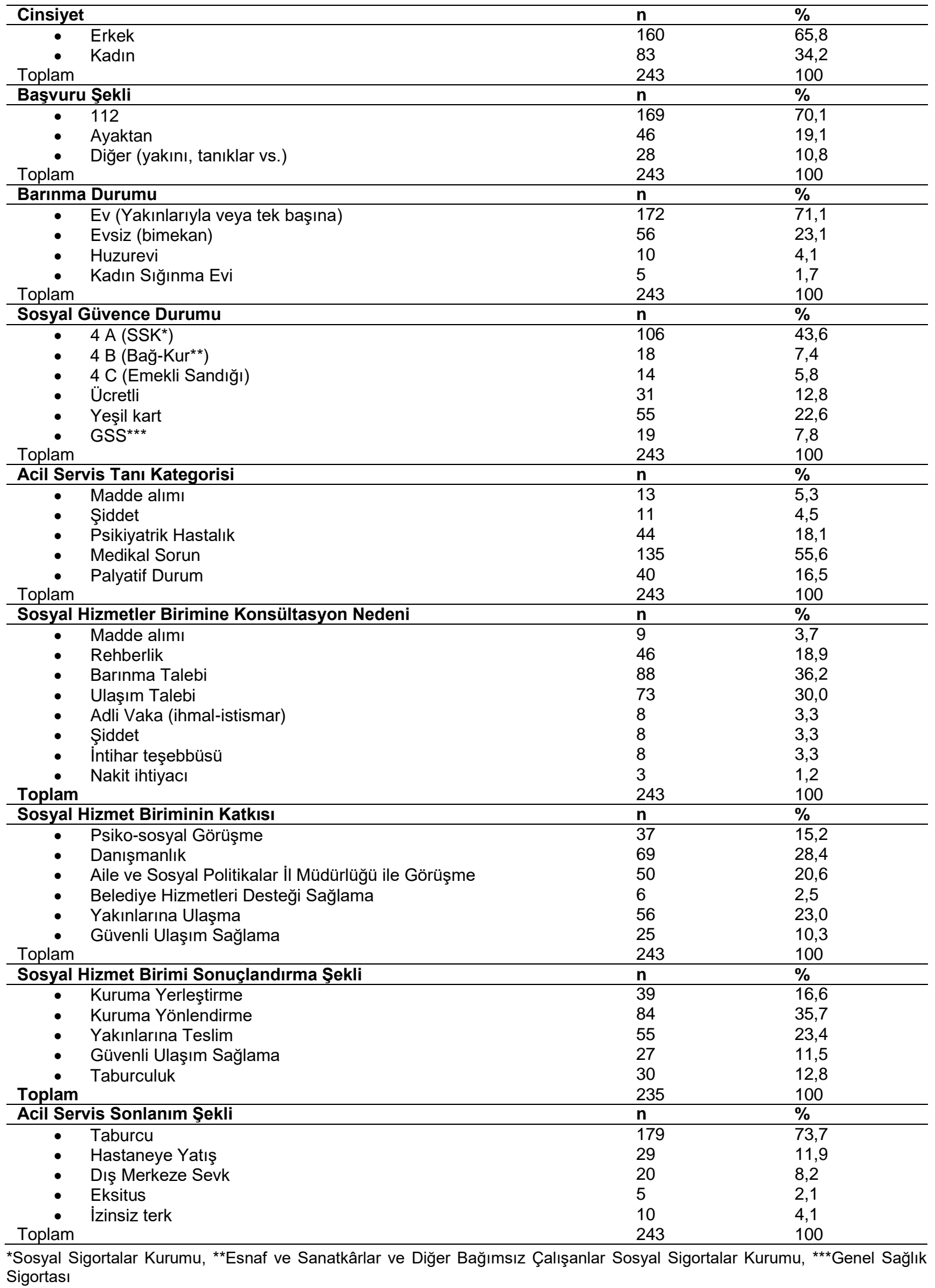


Hastalardan sosyal hizmet değerlendirmesi talebinin oluşturulmasının en sık nedenlerini sırasıyla barınma talebi $(\% 36,2)$, ulaşım talebi $(\% 30,0)$, rehberlik hizmetleri $(\% 18,9)$ oluşturdu. Sosyal hizmet birimi tarafından hastalara en sık; danışmanlık $(\% 28,4)$, hasta yakınlarına ulaşma (\%23), Aile, Çalışma ve Sosyal Hizmetler II Müdürlüğü ile temasa geçilmesi $(\% 20,6)$, psikososyal görüşme $(\% 15,2)$ şeklinde hizmet verildiği belirlendi. Hastaların sosyal hizmet birimi değerlendirmesi sonrası \% 35,7'sinin kuruma yönlendirildiği (n:84), \%23,4'ünün yakınlarına teslim edildiği (n:55), \%16,6'sının da kuruma yerleştirildiği (n:39) saptandı. Acil servisten hastaların \%73,7'sinin taburculuğu sağlanırken (n:179), \%20,1'inin hastaneye yatırıldığı ve $\% 2,1$ 'inin vefat ettiği (n:5) belirlendi. Hastaların acil serviste ortalama kalış süresi 61,2 \pm 79,7 saat (minimum:1, maksimum:580) olarak belirlendi. Çalışma verileri ile ilgili ayrıntılar Tablo1 'de sunuldu.

\section{TARTIŞMA}

Ülkemizde sosyal hizmet uzmanları 1965 yılında hastanelerde çalışmaya başlamıştır (6). Zamanla sosyal hizmet uzmanlarının hastane içerisindeki faaliyet alanları oldukça genişlemiştir ve gerontoloji, fiziksel tedavi ve rehabilitasyon, organ nakli, hemodiyaliz birimleri, sosyal pediatri gibi alanlarda çalışmaya başlamışlardır (7). Sosyal hizmet uzmanlarının hastane içerisindeki varlıkları bu kadar eskiye dayanmasına ve çalışma alanlarının giderek genişlemesine rağmen diğer sağlık çalışanları tarafından bilinirlikleri yüksek değildir. Yavuz ve ark. tarafından yapılan, hekim, hemşire ve diğer sağlık personellerinin dahil edildiği bir çalışmada katılımcıların \%46'sı hastanelerinde çalışan bir sosyal hizmet uzmanı olduğunu bilmediklerini belirtmiştir. Bu durum hekimler için \%39, ebehemşireler için de \%40 olarak saptanmıştır (8).

Sağlık Bakanlığı tarafından yayınlanan Tıbbi Sosyal Hizmet Uygulaması Yönergesine göre tıbbi sosyal hizmet: 'Ayakta ya da yatarak tedavi gören hastaların tıbbi tedaviden etkili bir şekilde yararlanması, sosyal sağlığının korunması ve geliştirilmesi, tedavi sürecinde hastanın ailesi ve çevresi ile ilişkilerinin düzenlenmesi, hastanın tedavi sürecini etkileyen psiko-sosyal ve sosyoekonomik sorunlarının zamanında çözümlenerek sosyal işlevselliğini yeniden kazanması amacı ile yürütülen sosyal hizmet uygulamasi' olarak tanımlanmaktadır. Aynı yönergede sosyal hizmet müdahalesi de: 'Bireyle, grupla, aileyle, toplumla sosyal hizmet ve sosyal hizmet araştırması yöntemlerinin kullanıldığı ve başvuru, inceleme, müdahale, değerlendirme, uygulama, sonuçlandırma ve izleme aşamalarının gerçekleştirildiği tıbbi sosyal hizmet uygulaması' olarak belirtilmektedir (9). Acil servisler yukarıdaki tanımlamalar dikkate alındığında sosyal hizmet desteği intiyacı duyulma olasılığı yüksek olan hastane birimleridir. Bu durum ülkemizde hem acil servis başvurularının nüfusa oranla yüksek olmasından hem de Acil servislerin hastane hizmetleri ile toplum arasında ara yüz vazifesi görmesinden kaynaklanmaktadır. Bu nedenle ihtiyacı olan hastalara zamanında müdahale edebilmek adına hızlı bir şekilde sosyal hizmet değerlendirmesine ulaşabilmek önem arz eder. Ancak bu durum hem ülkemiz de hem de uluslararası alanda yaygın değildir. Sosyal hizmet ihtiyacı olan hastalara sıklıkla mesai saatleri içerisinde hizmet verilebilmektedir (5) .

Ülkemizde acil servislerde en çok kimsesiz ve evsizlerin (bimekanların) barınma sorunlarının ortadan kaldırılması, hastaların acil servislerden nakil işlemlerinin gerçekleştirilmesi, kadına yönelik şiddet, istismar, çocuk inmali, intihar gibi durumlarda sosyal hizmet desteği sağlanmaktadır (10). Acil servislerde sosyal hizmet değerlendirmelerinin merkezinde hastaların maddi kısıtlılıklarından kaynaklanan sorunların giderilmesi bulunmaktadır (6). Çalışmamızdan elde ettiğimiz sonuçlarda da hastaların \%70'lik bir kısmında sosyal hizmet değerlendirmesi istenmesinin nedenini acil servisten taburculuk aşamasına gelen ve medikal sorunları giderilen hastaların barınma veya ikametlerine ulaşım sorunlarının oluşturduğu belirlenmiştir. Yani hastalar acil servisten sosyal nedenlerle taburcu edilemediklerinde sağlık çalışanlarının sosyal hizmet birimi desteği ihtiyacı hissettiği anlaşılmaktadır. Buna rağmen şiddet, intihar ve istismar gibi sorunların toplumdaki sıklığı göz önüne alındığında araştırmamızda bu faktörlere maruz kalan hasta gruplarına yeterli sosyal hizmet desteği sağlanamadığı düşünülmektedir.

Acil servisimizde sosyal hizmet uzmanı desteği mesai saatleri içerisinde gerçekleştirilmektedir. Tam zamanlı acil serviste çalışan bir sosyal hizmet görevlisi bulunmamaktadır. Araştırmamız 2012-2019 yılları arasında acil servisten sosyal hizmet uzmanı müdahalesi yapılan hastaları kapsamaktadır. Çalışmamız ile ilgili en çok dikkati çeken durum, sadece 2019 yılında yaklaşık 200.000 hastanın acil servisimize başvurduğu 
göz önüne alındığında, az sayıda hastanın sosyal hizmet uzmanı değerlendirmesine alınmış olmasıdır. Literatür verileri de göz önünde bulundurulduğunda bu duruma yol açabilecek olası etkenler; sağlık çalışanlarının sosyal hizmet uzmanı değerlendirmesi intiyacı olan hastaları fark etmelerindeki yetersizlik, hastanede sosyal hizmet değerlendirmesi yapılabildiğinin farkında olunmaması ve sosyal hizmet uzmanına sadece mesai saatleri içerisinde ulaşılması gibi faktörler olabilir. Gelecekteki çalışmalarda bu faktörlerin acil servislerde sosyal hizmet sunumu üzerine etkisi araştırılmalıdır.

Literatür verilerine bakıldığında acil servislerde tam zamanlı sosyal hizmet desteğinin sağlanmasının özellikle yüksek sayıda hasta başvurusu olan acil servislerde (>90.000 başvuru/yıl) maliyet açısından avantaj sağladığı, orta ve düşük sayıda hasta başvurusu olan acil servislerde ise (60.000 ve 30.000 başvuru/yıl) maliyet açısından belirgin bir fayda veya zarar elde edilmemekle birlikte sağlık personelinin zamanını etkin bir şekilde kullanabilmesine imkan sağladığı bildirilmektedir (2). Çalışmamızda değerlendirilen hastalar acil servisler açısından oldukça uzun sayılabilecek bir süre ( ortalama 61 saat) takip edilmek durumunda kalınmıştır. Her ne kadar konu ile ilgili maliyet araştırması yapılmasa da sosyal hizmet konsültasyonu sonrası hastaların acil servis sonlanışlarının sağlanabilir olmasının hastaların acil serviste geçirdikleri süreyi azaltmak açısından olumlu etki gösterdiği düşünülmektedir. Gelecek çalışmalarda klinisyenin hastanın sosyal hizmet gereksinimini başvuru anında fark etmesinin ve sosyal hizmet destek talebini erken başlatmasının acil serviste hasta kalış süreleri üzerine etkisi ile ilgili çalışmalar planlanabilir.

Çalışmanın tek merkezli olması bulguların genellenebilirliğini sınırlamaktadır. Aynı zamanda retrospektif nitelikte bir çalışma gerçekleştirilmiş olması verilerin doğruluğunu etkilemiş olabilir.

\section{SONUÇ}

Acil servislerde sosyal hizmet uzmanı değerlendirmesine intiyaç duyulur. Barınma ve ulaşım sorunları acil servisten en sık sosyal hizmet desteği istenme nedenleridir. Acil servis çalışanlarının sosyal hizmet uygulamalarının kapsamı hakkında farkındalıklarının artırılması gerekir. Acil servislerde tam zamanlı sosyal hizmet görevlilerinin daha fazla hastaya temas edebilmek için bulunması gereklidir.

Çıkar çatışması: Yazarlar çıkar çatışması beyan etmemişlerdir.

\section{KAYNAKLAR}

1- Bywaters P, Mcleod E, Fisher J, Cooke M, Swann G. Good intentions, increased inequities: Developing social care services in Emergency Departments in the UK. Heal Soc Care Community. 2011; 19 (5): 460-7.

2-Gordon JA. Cost-Benefit Analysis of Social Work Services in the Emergency Department: A Conceptual Model. Academic Emergency Medıcıne. 2001; 8 (1): 54-60.

3- Moore M, Whiteside LK, Dotolo D, et al. The role of social work in providing mental health services and care coordination in an urban trauma center emergency department. Psychiatr Serv. 2016; 67 (12): 1348-54.

4- Mahajan P, Stanley R, Ross KW, Clark L, Sandberg K, Lichtenstein R. Evaluation of an Emergency Department-Based Enrollment Program for Uninsured Children. Annals ofEmergency Medicine.2005; 45 (3): 245-50.

5- Wong TW, Chung M, Chan C. A survey of medical social services in local Accident and Emergency departments. Hong Kong Journal of Emergency Medicine. 2001; 8 (3): 135-39.

6- Özbesler C, İçağasioğlu ÇA. Hastane Ortamında Sosyal Hizmet Uygulamaları: Ankara Örneği. Toplum ve Sosyal Hizmet. 2010; 21 (2): 31-46.

7- Özbesler C. Hasta Yaşam Kalitesinde Tıbbi Sosyal Hizmet Uygulamalarının Önemi. Tıbbi Sosyal Hizmet Dergisi. 2013; 2 (2): 6-12.

8- Yavuz B, Çakın E, Çalgı B, Doğan S, Özüçelik DN. Hastanede Sosyal Hizmet Uzmanı Ve Tıbbi Sosyal Hizmet Farkındalığının Değerlendirilmesi. Afet ve Acil Tıp Derneği Dergisi. 2020; 1 (3): 23-38.

9-Tıbbi Sosyal Hizmet Uygulama Yönergesi. Web adresi: https://dosyasb.saglik.gov.tr/Eklenti/1349,img071372pdf.pdf?0 Erişim tarihi:24.05.2021.

10-Yıldırım B, Başer AO. Acil Servis Tıbbi Sosyal Hizmet Müdahaleleri, Müracaatçı Profili ve Sosyal Hizmet Mülakatında Dikkat Edilmesi Gereken Durumlar. Toplum ve Sosyal Hizmet. 2019; 30 (1): 286-308. 